\title{
RUÍNAS DE SÃO MIGUEL DAS MISSÕES/RS E FORMAÇÃO DOCENTE \\ a saída de campo como recurso pedagógico interdisciplinar nos anos iniciais
}

\author{
Rosemar de Fátima Vestena ${ }^{1}$ \\ Ail Conceiçao Meireles Ortiz ${ }^{2}$ \\ Eliane Aparecida Galvão dos Santos ${ }^{3}$
}

\begin{abstract}
Resumo: As reflexões acerca dos saberes e vivências voltadas às áreas das Ciências Humanas e da Natureza, na formação inicial de professores em Pedagogia, é de extrema relevância tanto para a inserção de conhecimentos de Geografia, História, Arte e Ciências no currículo escolar dos anos iniciais, como também para sensibilizar os acadêmicos quanto ao desenvolvimento da cidadania em diferentes espaços educacionais. Nesse sentido, oportunizar aos acadêmicos momentos de interlocução entre teoria e prática, por meio de recursos didáticos, como as saídas de campo, podem favorecer uma nova postura docente nos anos iniciais do ensino fundamental. Nesses termos, este trabalho objetiva identificar e analisar quais os conhecimentos espaçotemporais, sociocientíficos e artístico-culturais são evidenciados pelos estudantes de Pedagogia a partir de uma visita técnica orientada ao sítio histórico das Ruínas de São Miguel das Missões (RSMM), RS, no segundo semestre de 2017. A pesquisa é de abordagem qualitativa e cunho bibliográfico e documental. Como material de análise, utilizaram-se 19 resumos, de modo não excludente, produzidos por 57 estudantes reunidos em grupos, demonstrando seus conhecimentos acerca da viagem de estudo. Para análise dos dados, partiu-se de três categorias pré-estabelecidas, i) conhecimentos espaço-temporais, ii) conhecimentos sociocientíficos e iii) conhecimentos artístico-culturais. Identificou-se, dentre os 19 resumos produzidos pelos acadêmicos, que 13 contêm informações e análises acerca da categoria artístico-cultural. Já a categoria espaço-temporal está presente em seis (06) resumos e a categoria sociocientífica, em apenas dois (02) resumos. Defende-se que, na formação inicial de docentes, é necessário abordar metodologias interdisciplinares e recursos didáticos, como visitas técnicas orientadas, que potencializem experiências didáticas capazes de correlacionar saberes teóricos e práticos na formação inicial dos estudantes, visando a transpô-los para os espaços da educação básica.
\end{abstract}

Palavras-chave: Ciências Humanas e da Natureza. Pedagogia. Metodologia de Ensino.

\section{THE RUINS OF SAO MIGUEL DAS MISSOES/RS AND TEACHER EDUCATION field trip as an interdisciplinary teaching resource in the initial years}

Abstract: Reflections on the knowledge and experiences with regard to the areas of Human Sciences and Nature in the initial education of Pedagogy teachers are extremely relevant for the

\footnotetext{
${ }^{1}$ Doutora em Educação em Ciências Química da Vida e Saúde. Mestre em Educação e docente do Curso de Pedagogia e do Programa de Pós-Graduação em Ensino de Ciências e Matemática da Universidade Franciscana, Santa Maria, RS. E-mail: rosemarvestena@gmail.com

${ }^{2}$ Mestre em Educação e docente dos cursos de Pedagogia e Geografia da Universidade Franciscana, Santa Maria, RS. E-mail: ail@unifra.br

${ }^{3}$ Doutora em Educação e Mestre em Educação. Docente do curso de Pedagogia e do Mestrado em Ensino de Humanidades e Linguagens da Universidade Franciscana, Santa Maria, RS. E-mail: elianeagalvao1@gmail.com
} 


\section{REVISTA ELETRÔNICA \\ DA GRADUAÇÃO/PÓS-GRADUAÇÃO EM EDUCAÇÃO UFG/REJ}

insertion of knowledge of Geography, History, Art and Sciences in the school curriculum of the initial years in order to sensitize scholars as entrepreneurs of citizenship in different educational spaces. Therefore, providing students with opportunities to relate theory to practice through learning resources such as field trips may contribute to a new teaching attitude, thus reaching the basic education classrooms with knowledge of areas that are not always prioritized in the early years of elementary school. This paper aims to discuss the historical-geographic, socioscientific and artistic-cultural knowledge revealed by students of Pedagogy in consequence of a guided technical visit to the historical site of the Ruins of Sao Miguel das Missões, RS in the second half of 2017. The nature of this research is qualitative and so it explores bibliographic and documentary methods. The data analysed included 19 non-excluding summaries written by 57 students, which were grouped together. The writings focused on the students' knowledge of the study trip. To analyse data, these three pre-established categories were followed: 1) spatiotemporal knowledge; 2) socio-scientific knowledge; and 3) artistic-cultural knowledge. It was identified among the 19 abstracts produced by the academics, which in 13 of them contained information and analysis about the artistic-cultural category. The spatio-temporal category is present in six (06) abstracts and the socio-scientific category, in only two (02) abstracts. It has been argued that, in the initial teacher education, it is necessary to approach interdisciplinary methodologies and learning resources such as guided technical visits, since they may improve learning experiences which are capable of correlating theoretical and practical knowledge, thus transposing this understanding to basic education as well.

Keywords: Human and Nature Sciences. Pedagogy. Teaching Methodology.

\section{INTRODUÇÃO}

$\mathrm{Na}$ formação docente em Pedagogia, segundo a Resolução $\mathrm{n}^{\mathrm{o}}$ 1, de 2006 (BRASIL, 2006), que trata das Diretrizes Curriculares para o curso de Pedagogia (DCCP), consta, como orientações para o núcleo de estudos básicos, a decodificação e utilização de códigos de diferentes linguagens utilizadas por crianças, além do trabalho didático com conteúdos pertinentes aos primeiros anos de escolarização, relativos à Língua Portuguesa, Matemática, Ciências, História e Geografia, Artes e Educação Física. Essa premissa parte da necessidade de aprofundamento dos estudos do futuro pedagogo em áreas específicas do conhecimento, para poder ensinar às crianças português, matemática, ciências, história, geografia, dentre outros componentes curriculares.

Os currículos dos cursos de Pedagogia procuram atender às orientações das DCCP por meio de disciplinas, as quais contemplam geralmente unidades que mesclam conteúdos específicos de cada área e métodos de ensino. Objetivam propor aos estudantes não só o aprendizado dos conteúdos e a vivência de métodos de ensino, como também aprenderem a transpor esses conhecimentos especialmente aos alunos dos primeiros anos escolares. Assim, os cursos necessitam, ao longo dos semestres letivos, 


\section{REVISTA ELETRÔNICA \\ DA GRADUAÇÃO/PÓS-GRADUAÇÃO EM EDUCAÇÃO UFG/REJ}

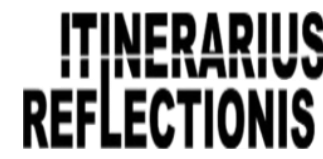

ISSN. 1807-9342

Volume 14, N. 2, 2018

oportunizar propostas didáticas diferenciadas, pautando temas, objetivos e recursos didáticos, numa perspectiva de experienciá- las e efetivá-las nos diferentes contextos de exercício docente desses futuros professores (BRASIL, 2006).

Atualmente, são muitos os recursos didáticos disponíveis para auxiliar no processo de ensino e aprendizagem. Como exemplos, pode-se citar desde os mais tradicionais, como o quadro e o giz, os livros didáticos, atividades experimentais, saídas a campo, objetos virtuais, sites, jogos e visitas virtuais e aqueles (re)criados pelo professor. Assim, a escolha por uma ou outra alternativa didática depende dos objetivos de ensino e aprendizagem e da proposta metodológica pautada pelo professor. Dentre os recursos didáticos anunciados anteriormente, destacam-se, para fins desta pesquisa, as saídas de campo.

Viveiro e Diniz (2009), ao se referirem às saídas de campo que envolvem estudantes da graduação, salientam que este é um recurso importante como aliado docente, por agregar um componente dinamizador no processo de formação inicial de futuros professores, visto que contempla conteúdos disciplinares (prática e teoria), junto à motivação de estudantes pelo contato direto com o local de estudo para a compreensão de fenômenos naturais e sociais, vislumbrando possibilidades de transpô-los em diferentes contextos educacionais. Além disso, constitui-se como uma importante alternativa de desenvolver, nos futuros professores, a observação seguida de questionamentos e reflexões acerca dos objetos e locais de estudo, o respeito, a iniciativa para a pesquisa e de colocar a inclusão do estudante em contato direto com os objetos de estudo para o desenvolvimento de habilidades de observação, descrição, comparação, percepção, registro e conclusões e, paralelamente, valer-se de análises contextualizadas e interdisciplinares.

Contudo, objetiva-se com este estudo identificar e analisar quais os conhecimentos espaço-temporais, sociocientíficos e artístico-culturais são evidenciados pelas estudantes de Pedagogia, ao visitarem o sítio histórico das Ruínas de São Miguel das Missões, RS, no segundo semestre de 2017.

A pesquisa é de abordagem qualitativa e cunho bibliográfico e documental. Como material de análise, utilizaram-se 19 resumos, de modo não excludente, produzidos por 57 estudantes, demonstrando seus conhecimentos acerca da viagem de estudo ao sítio histórico das Ruínas de São Miguel das Missões, RS. 


\section{REVISTA ELETRÔNICA \\ DA GRADUAÇÃO/PÓS-GRADUAÇÃO EM EDUCAÇÃO \\ UFG/REJ}

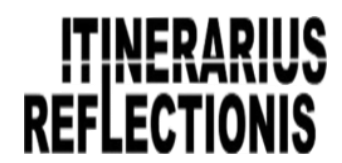

ISSN. 1807-9342

Volume 14, N. 2, 2018

$\mathrm{O}$ artigo traz, em um primeiro momento, algumas reflexões acerca da formação docente em Pedagogia. Destaca a articulação entre conteúdos, métodos e recursos didáticos, enfocando, especialmente, a estratégia didática de saídas de campo. $\mathrm{Na}$ sequência, aborda a metodologia de pesquisa. E, para finalizar, apresenta a análise dos dados e as considerações finais.

\section{CONTEÚDO E MÉTODO NA FORMAÇÃO DOCENTE}

$\mathrm{Na}$ etapa de formação inicial de docentes, é pertinente extrapolar os locais acadêmicos e acessar, na comunidade em geral, outros espaços formais e não formais de educação. Visa-se, nessa etapa de formação, a desenvolver, junto ao futuro professor, maior autonomia didático-pedagógica por meio de uma identidade pessoal, profissional e organizacional da profissão docente. "Estar em formação implica um investimento pessoal, um trabalho livre e criativo sobre os percursos e os projetos próprios, com vista à construção de uma identidade, que é também uma identidade profissional" (NÓVOA, 1992, p.13).

As vivências acadêmicas promovidas na formação inicial de professores de Pedagogia estão para além da construção e articulação de conhecimentos acadêmicos em si, pois contemplam, na projeção desses saberes, o exercício docente no ambiente escolar, mais especificamente na educação infantil e nos anos iniciais do ensino fundamental.

Nos primeiros anos escolares, precisa-se atender às concepções sociocognitivas dos estudantes por meio da estrutura curricular e propostas de trabalho. Nessa intencionalidade pedagógica, é necessário promover a construção de noções conceituais e o desenvolvimento de habilidades básicas, que possam garantir um processo gradual e progressivo da aprendizagem. Assim reforça Cavalcanti (2003, p.25): “o ensino é um processo de conhecimento pelo aluno, mediado pelo professor e pela matéria de ensino, no qual devem estar articulados seus componentes fundamentais: objetivos, conteúdos e métodos de ensino". Isso exige, por parte dos pedagogos, estruturas conceituais e metodológicas capazes de embasar o currículo escolar na educação infantil e anos iniciais, envolvendo, portanto, os conhecimentos de bases teóricas e metodológicas 


\section{REVISTA ELETRÔNICA \\ DA GRADUAÇÃO/PÓS-GRADUAÇÃO EM EDUCAÇÃO \\ UFG/REJ}

\section{ITHERARIIS \\ REFLECTIONIS}

ISSN. 1807-9342

Volume 14, N. 2, 2018

norteadoras do Ensino de Ciências da Natureza, das Ciências Humanas, das Linguagens e da Matemática.

Delizoicov, Angotti e Pernambuco (2002), ao se referirem aos saberes e habilidades de um futuro professor, destacam conteúdos, metodologias e recursos didáticos alinhados com propostas pedagógicas que fomentem, nos estudantes, conhecimentos mais contextualizados, plausíveis e frutíferos para construção da autonomia e cidadania dos mesmos. No caso da educação geográfica, que tem como objeto de estudo o espaço na sua totalidade, evidencia-se a relação entre a sociedade e a natureza, contribuindo para a formação de uma consciência mais crítica. Essa visão sobre o espaço geográfico abrange uma compreensão inter-relacionada de aspectos físico-naturais, socioeconômicos, políticos, históricos e ambientais.

Segundo Cavalcanti (2002), o ensino de Geografia tem como finalidade trabalhar junto aos estudantes as referências adquiridas na escola e na sociedade e sistematizá-las, observando e analisando a sociedade e o cotidiano para, assim, criar um pensar geográfico crítico. É importante ressaltar que a Geografia é uma ciência humana e, portanto, debruçada sobre problemas que afetam a sociedade como guerras, segregações sociais, crise habitacional, condições de vida urbana e rural, dentre outras, as quais clamam por soluções efetivas. Assim, a Geografia estuda a diversidade do mundo atual sem, contudo, deixar de considerar a dimensão espacial, mas, a partir das questões espaciais, trazer o ser humano como produtor de espaço marcado por quem o produz (FILIZOLA; KOZEL, 2009).

Contudo, concebe-se o processo de ensino e aprendizagem como um meio de desenvolver a cidadania nos estudantes. Assim, é pertinente refletir acerca do papel da alfabetização científica nas escolas que, segundo Chassot (2000), alfabetizar cientificamente significa ler e interpretar o mundo por meio das lentes das ciências, para que o estudante interaja na sociedade com maior autonomia. No entanto, para entender a realidade social e poder intervir com responsabilidade cidadã, é necessário aliar conhecimentos de modo articulado, especialmente entre as ciências humanas e da natureza. Desse modo, os estudantes, independentemente do nível de ensino e de alfabetização em que se encontrem, necessitam de uma formação científica e humana mais contextualizada e crítica, para interagir no seu entorno, como também, de modo 


\section{REVISTA ELETRÔNICA \\ DA GRADUAÇÃO/PÓS-GRADUAÇÃO EM EDUCAÇÃO UFG/REJ}

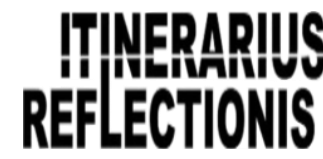

ISSN. 1807-9342

Volume 14, N. 2, 2018

mais ampliado no mundo, dependendo das oportunidades e desafios que lhes são apresentados (KRASILCHIK; MARANDINO, 2010).

No contexto educacional, existem diversos recursos didáticos disponíveis que permitem colocar o estudante em contato de modo mais concreto possível com os objetos de estudo. Nas salas de aula, os professores podem propor atividades experimentais, uso de maquetes e moldes anatômicos, modelos didáticos que simulem realidades e fenômenos naturais e sociais.

No entanto, segundo Salles e Kovaliczen (2007), as saídas de campo são recursos didáticos que oportunizam aos estudantes o contato direto com a realidade de estudo, permitindo o desencadear de posturas científicas, éticas e cidadãs, uma vez que poderão desenvolver responsabilidades e cooperação e, assim, aprender a participar da vida comunitária.

Em se tratando do trabalho docente realizado com as crianças, a saída de campo representa uma ferramenta impulsionadora da criticidade, da consciência coletiva e do desenvolvimento do pensamento e da atitude científica, pois o olhar perceptivo e examinador da criança em desenvolvimento, no momento em que estão em formação as estruturas cognitivas constituintes do pensamento científico, exige atividades que impulsionem a descoberta. Essas possibilidades proporcionam a base para a compreensão de ciência e vivência de valores sociais (SCHÄFFER, 2001).

O trabalho de campo constitui uma atividade instigadora na construção de importante categoria conceitual, denominada espacialidade, provocando a associação de fundamentos construídos, ao longo do trabalho escolar, à realidade próxima. O estudo do meio possibilita a visualização da organização espacial local, como oportunidade de conhecimento e análise globalizada de aspectos físico-naturais, socioeconômicos, histórico-culturais e ambientais.

$\mathrm{Na}$ análise geográfica, os espaços percebidos, concebidos e vividos não são lineares. Portanto, é necessário romper com essa concepção para possibilitar uma leitura geo-histórica dos fatos e uma análise com abordagens históricas, sociológicas e espaciais (geográficas) simultâneas. Retomar o sentido dos espaços percebidos, concebidos e vividos nos permite reconhecer os objetos, os fenômenos e os lugares distribuídos no território e compreender os diferentes olhares para os arranjos desses objetos nos planos espaciais (BRASIL, 2018, p.351). 


\section{REVISTA ELETRÔNICA \\ DA GRADUAÇÃO/PÓS-GRADUAÇÃO EM EDUCAÇÃO UFG/REJ}

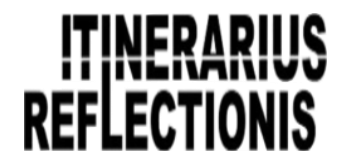

ISSN. 1807-9342

Volume 14, N. 2, 2018

Os processos educativos escolares precisam ser qualificados por situações que propiciem a análise e interpretação de lugares próximos, bem como de lugares mais distantes. Conforme Schäffer (2001), o trabalho de campo é uma possibilidade de superar a fragmentação do conhecimento, pois apresenta o estudo da realidade a partir de múltiplos aspectos que podem ser explorados pelas diversas áreas do conhecimento escolar, por meio da ação coletiva dos professores, mas que têm objetivos similares. Assim, a atividade de saída de campo pode ser considerada um método ativo e interativo, porque requer um trabalho interdisciplinar. Segundo Cavalcanti (2002, p. 90):

Estudar o meio, o meio ambiente, a realidade, a vida (ou qualquer que seja o vocabulário escolhido) significa tentar encontrar elementos para melhor compreender a interação do homem com o mundo, o que faz a partir de determinado ponto de vista ou enfoque teórico.

O estudo do meio mobiliza, em primeiro lugar, as sensações e percepções dos alunos no processo de conhecimento para, em seguida, perceber-se a elaboração conceitual. É necessário atenção aos objetivos desse procedimento e ao encaminhamento de suas atividades, para que sejam adequadas às possibilidades e necessidades dos estudos realizados. Para tanto, é preciso planejar o trabalho de campo e estar atento às etapas a serem realizadas. Os procedimentos metodológicos voltados para a apreensão da realidade empírica constituem-se em aspectos fundamentais na reconstituição de uma visão global, a partir do entorno do observador. Portanto, a saída de campo compreende um instrumento didático que enriquece o trabalho do professor, propiciando ao aluno desenvolver uma série de competências, como observar, avaliar, criar hipóteses, a fim de levantar sugestões, enfim entender o universo onde vive.

\section{METODOLOGIA}

A pesquisa caracteriza-se por uma abordagem qualitativa de cunho bibliográfico e documental. De acordo com Bogdan e Biklen (1994), os documentos podem ser contemporâneos ou retrospectivos e também fontes de primeira mão (que não receberam qualquer tratamento analítico), tais como: documentos oficiais, reportagens de jornal, cartas, contratos, fotografias, gravações, gravuras, pinturas a óleo, desenhos técnicos, etc.; ou fontes de segunda mão (os que de alguma forma já foram analisados), 


\section{REVISTA ELETRÔNICA \\ DA GRADUAÇÃO/PÓS-GRADUAÇÃO EM EDUCAÇÃO \\ UFG/REJ}

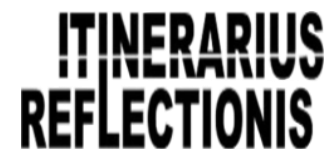

ISSN. 1807-9342

Volume 14, N. 2, 2018

tais como: relatórios, tabelas estatísticas, manuais, pareceres de perito, decisões de juízes, entre outros.

No caso deste trabalho, os registros (resumos dos estudantes) são considerados fontes de primeira mão, pois são analisados pela forma como foram produzidos pelos alunos, para fins de avaliação final das disciplinas ao final do semestre do curso. Os resumos foram analisados e comparados para evidenciar, descrever e inferir fatos científicos, sociais, artísticos, históricos e geográficos, estabelecendo correlações, características e tendências.

As atividades foram desenvolvidas, no segundo semestre letivo de 2017, por um curso de Pedagogia de uma universidade da região central do Rio Grande do Sul, Brasil, nas quais participaram 57 estudantes do sexo feminino.

No início do segundo semestre de 2017, os docentes ministrantes das disciplinas de Metodologia de Ensino de Ciências, Metodologia de Ensino de Arte, Metodologia de Ensino de História e Geografia e Metodologia de Ensino da Língua Portuguesa elaboraram, de forma conjunta, um projeto interdisciplinar para a construção, por parte das estudantes, de conhecimentos tanto de conteúdos quanto de metodologias de ensino. No projeto, desenvolveram-se, ao longo do semestre, conhecimentos de aspectos históricos, geográficos, ambiental, artístico e literário, especialmente acerca do local priorizado para o estudo, que foi o sítio histórico das Ruínas de São Miguel das Missões (RSMM). Assim, houve a apresentação, por parte dos docentes, do roteiro de visitação técnica, das formas de coleta de dados, formas de organização dos dados, apresentação dos resultados à coletividade e critérios de avaliação das atividades.

No projeto interdisciplinar, as estudantes foram envolvidas em basicamente três etapas. A etapa de preparação (sensibilização) para os estudos, visando à saída de campo, por meio de atividades como palestras, filmes e realização de leituras e seminários para aprofundar conhecimentos acerca das RSMM. Na sequência, participaram da viagem propriamente dita, em que tiveram a oportunidade de vivenciar e estudar in loco o que vinha sendo sinalizado por meio de diferentes recursos durante o transcorrer do semestre. E, por fim, participaram da etapa de sistematização dos conhecimentos construídos.

No entanto, como documentos de análise para essa pesquisa, foram utilizados apenas os 19 resumos (material didático) produzidos pelos grupos das acadêmicas e 


\section{REVISTA ELETRÔNICA \\ DA GRADUAÇÃO/PÓS-GRADUAÇÃO EM EDUCAÇÃO \\ UFG/REJ}

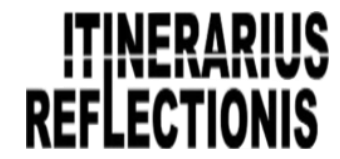

ISSN. 1807-9342

Volume 14, N. 2, 2018

entregues no final do semestre aos docentes, como um dos critérios de avaliação de aprendizagem das disciplinas. Para a elaboração dos mesmos, as 57 estudantes foram reunidas em grupos de aproximadamente três (03) componentes, totalizando 19 resumos.

No final, os 19 resumos deram origem a 19 pôsteres que serviram de recurso para a socialização dos registros e análises à comunidade acadêmica. A Figura 1 exibe a exposição dos pôsteres, apresentados à comunidade acadêmica da instituição, no dia 14 de novembro de 2017.

Figura 1: Pôsteres apresentados pelas estudantes à comunidade acadêmica da instituição.

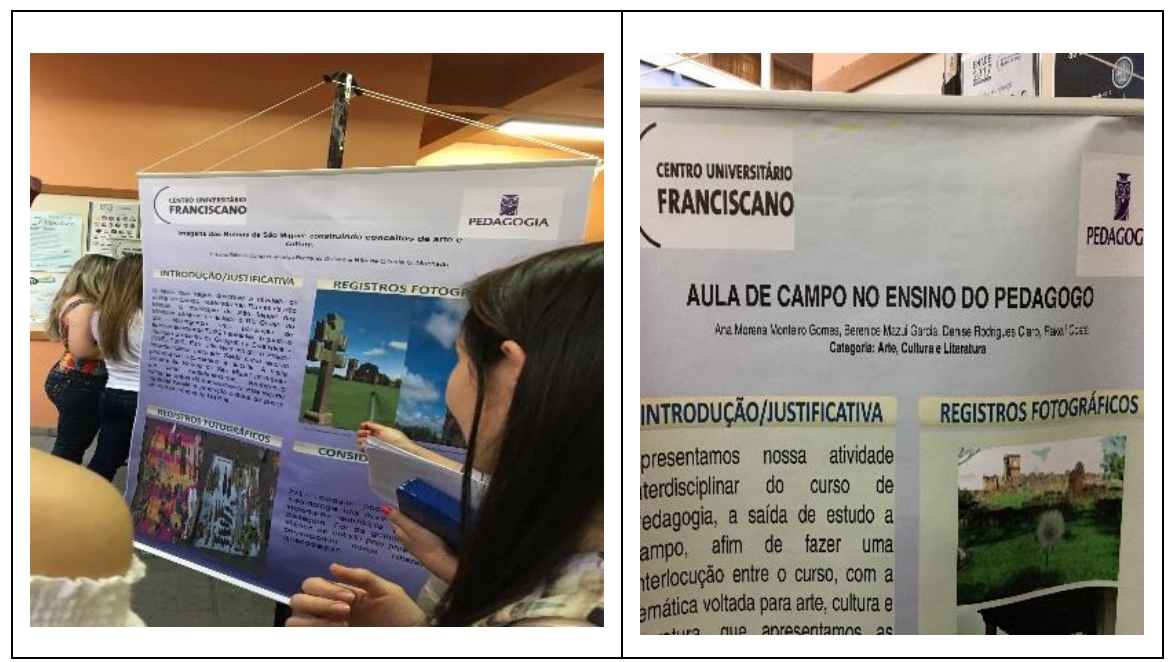

Fonte: As autoras.

Destaca-se que, como ilustração deste artigo, foram utilizadas fotografias de alguns pôsteres, pois esses compilam imagens e textos dos respectivos resumos das acadêmicas, porém, para especificar e detalhar as análises das estudantes, foram extraídos excertos dos resumos que são identificados pela letra $R$, seguida de um número arábico (R 1, R2, R3 ...).

Para a análise dos resumos, utilizaram-se, conforme orienta Bardin (2016), categorias pré-estabelecidas, aqui denominadas sociocientíficas, espaço-temporais, artístico-culturais, descritas no Quadro 1. Ainda, segundo Bardin (2016), a partir das categorias explicitadas no Quadro1, emergiram subcategorias, nas quais evidenciaramse os conhecimentos que foram priorizados (identificados) e discutidos em cada categoria pelos estudantes. 


\section{REVISTA ELETRÔNICA \\ DA GRADUAÇÃO/PÓS-GRADUAÇÃO EM EDUCAÇÃO \\ UFG/REJ}

\section{ITHERAPIIIS \\ REFLECTIONIS}

ISSN. 1807-9342

Volume 14, N. 2, 2018

Quadro 1: categorias e conhecimentos: referências para orientação da visita técnica

\begin{tabular}{|c|c|}
\hline CATEGORIAS & CONHECIMENTOS \\
\hline Sociocientíficas (SC) & $\begin{array}{l}\text { Observa os conhecimentos das estudantes alinhados à área das } \\
\text { ciências como fauna, flora, biomas e impactos ambientais } \\
\text { causados pela ação humana. Essa dimensão compreende a } \\
\text { biodiversidade regional, envolvendo aspectos relacionados à } \\
\text { flora, fauna e ambiente. Espécies de animais seus respectivos } \\
\text { nichos e habitat, as árvores em geral, as plantas epífitas, } \\
\text { gramíneas, as samambaias, os musgos, os órgãos vegetais } \\
\text { como flores, frutos, sementes e raízes. Analisa rios, lagos, } \\
\text { cachoeiras, campos, plantações em área rural ou em ambientes } \\
\text { urbanos, bem como, edificações, estradas, ruas, etc. com ou } \\
\text { sem a presença humana e de outros seres vivos. }\end{array}$ \\
\hline Artístico-culturais (AC) & $\begin{array}{l}\text { Essa dimensão analisa os aspectos relacionados ao patrimônio } \\
\text { artístico e cultural imaterial da humanidade que são as Ruínas } \\
\text { de São Miguel da Missões, observando a arte e arquitetura no } \\
\text { que se refere ao estilo barroco e à amalgama entre a arte de } \\
\text { influência europeia e a indígena, presentes na igreja, na arte } \\
\text { sacra, nas esculturas e no design de objetos. Também, envolve } \\
\text { a literatura no Brasil, no século XVII, que, permeada pela } \\
\text { influência da arte barroca, produziu prosa e poesia } \\
\text { especialmente por meio dos sermões do Padre Antônio Vieira } \\
\text { e dos poemas de Gregório de Matos. }\end{array}$ \\
\hline Espaço-temporais (ET) & $\begin{array}{l}\text { Essa dimensão destaca as percepções acerca das feições da } \\
\text { paisagem local, tanto de caráter físico-natural, socioeconômico } \\
\text { e ambiental, bem como testemunhos da história local. Observa } \\
\text { a paisagem composta de aspectos cartográficos (mapa do } \\
\text { local), aspectos físico-naturais (forma de relevo, cursos d'água, } \\
\text { formações vegetais e tipo de clima), aspectos socioeconômicos } \\
\text { e culturais (étnicas, atividades econômicas predominantes, } \\
\text { gastronomia, etc.), aspectos históricos (monumentos, prédios } \\
\text { religiosos, museus, dentre outros) e aspectos ambientais } \\
\text { (cenários de preservação e de degradação do ambiente). A } \\
\text { apreensão de espacialidade que abrange, ainda, a constatação } \\
\text { da identidade do lugar São Miguel das Missões. }\end{array}$ \\
\hline
\end{tabular}

Fonte: As autoras.

Assim, procurou-se evidenciar, nos resumos das acadêmicas, na categoria SC, se as estudantes observaram aspectos como a fauna, a flora, os biomas e impactos ambientais ocasionados pela ação humana. Na categoria AC, se as acadêmicas analisaram a arquitetura, esculturas das reduções jesuíticas, bem como as influências indígenas e jesuíticas no passado e no presente na região das missões do RS. E, na categoria ET, se as alunas perceberam os aspectos históricos, a paisagem, localização e impactos econômicos e ambientais. 


\section{REVISTA ELETRÔNICA \\ DA GRADUAÇÃO/PÓS-GRADUAÇÃO EM EDUCAÇÃO \\ UFG/REJ}

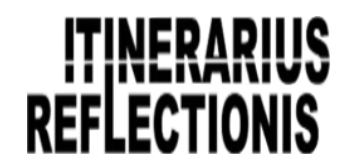

ISSN. 1807-9342

Volume 14, N. 2, 2018

\section{ANÁLISE DOS DADOS}

Dentre os 19 resumos, observou-se que a categoria Artístico-cultural (AC) foi evidenciada em 13. A categoria Espaço-temporais (ET) esteve presente em seis resumos e a categoria Sociocientífica (SC), em apenas dois resumos.

$\mathrm{Na}$ categoria AC, as estudantes expressaram, nos resumos, a valorização do patrimônio histórico e cultural das ruínas, esculturas e artesanato, fruto da influência das reduções jesuíticas e da presença dos índios guaranis na região. Na categoria ET, as estudantes perceberam os aspectos históricos, a paisagem, localização e impactos econômicos e ambientais. Na categoria SC, foi observada e discutida a biodiversidade e os impactos ambientais.

A Figura 2 sumariza as categorias com as respectivas temáticas (subcategorias), observadas e discutidas pelas acadêmicas nos 19 resumos.

Figura 2: Categorias e subcategorias evidenciadas nos resumos das acadêmicas.

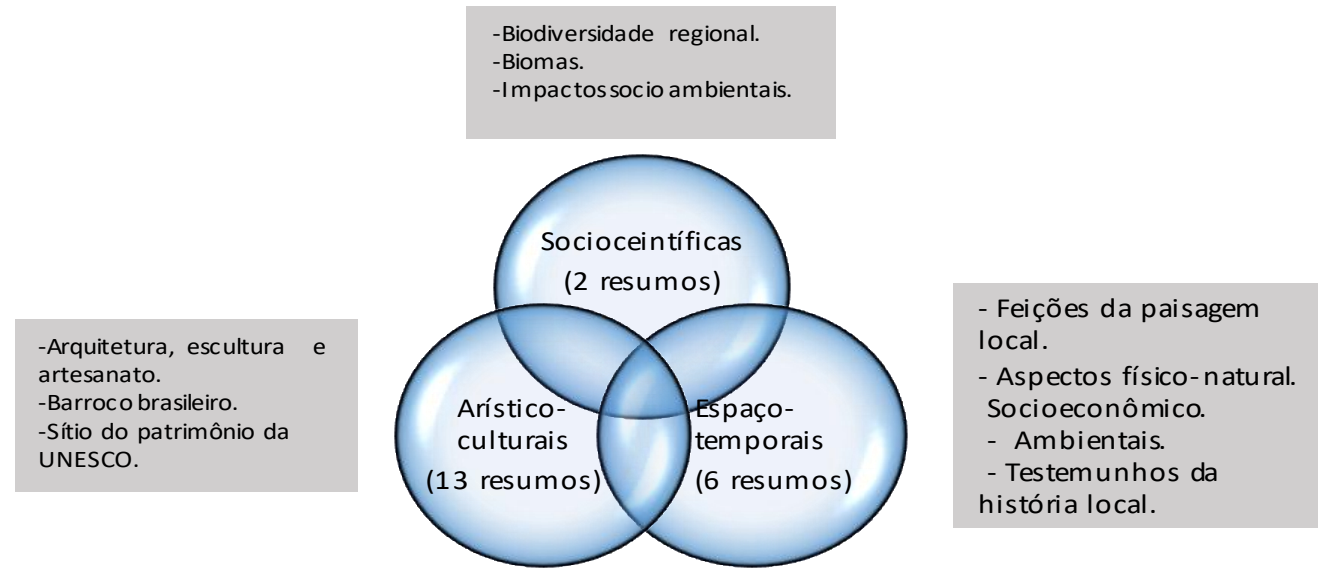

Fonte: As autoras.

Com relação às análises e reflexões das acadêmicas acerca da categoria AC (13 resumos), observou-se que a escolha do local com o sítio arqueológico das Ruínas de São Miguel, RS, contribuiu por si só para o foco das estudantes nesses aspectos, uma vez que, no local, são evidentes a arquitetura barroca e o contexto histórico e cultural, atestados pelas ruínas, pelas esculturas e objetos expostos, pelo espetáculo de som e luz, apresentado no final da visita e pelo fato de ter sido uma visita técnica, orientada por uma guia local, a qual procurou salientar os aspectos históricos, artísticos e culturais da 


\section{REVISTA ELETRÔNICA \\ DA GRADUAÇÃO/PÓS-GRADUAÇÃO EM EDUCAÇÃO \\ UFG/REJ}

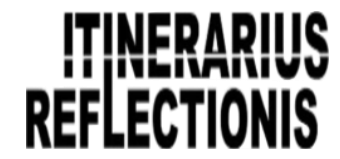

ISSN. 1807-9342

Volume 14, N. 2, 2018

região. Também se alinhou com a etapa preparatória das acadêmicas, planejada pelo curso para servir de sensibilização para a atividade interdisciplinar de saída de campo rumo às RSMM. Na ocasião, houve uma palestra com uma professora com formação em história e geografia para discorrer acerca dos aspectos geográficos e do patrimônio histórico, artístico e cultural da região das missões do RS. Além disso, as temáticas levantadas no início da proposta interdisciplinar foram, ao longo do semestre, discutidas e aprofundadas nas disciplinas, especialmente em Ensino de Artes Visuais, Cênicas e Musicais, Ensino de Língua Portuguesa, Ensino de História e Geografia.

A Figura 3 exemplifica alguns aspectos discutidos na categoria referente às questões $\mathrm{AC}$, que serão pormenorizados nos excertos dos resumos que seguem para sustentar as análises.

\section{Figura 3: Pôsteres aspectos artístico-culturais}

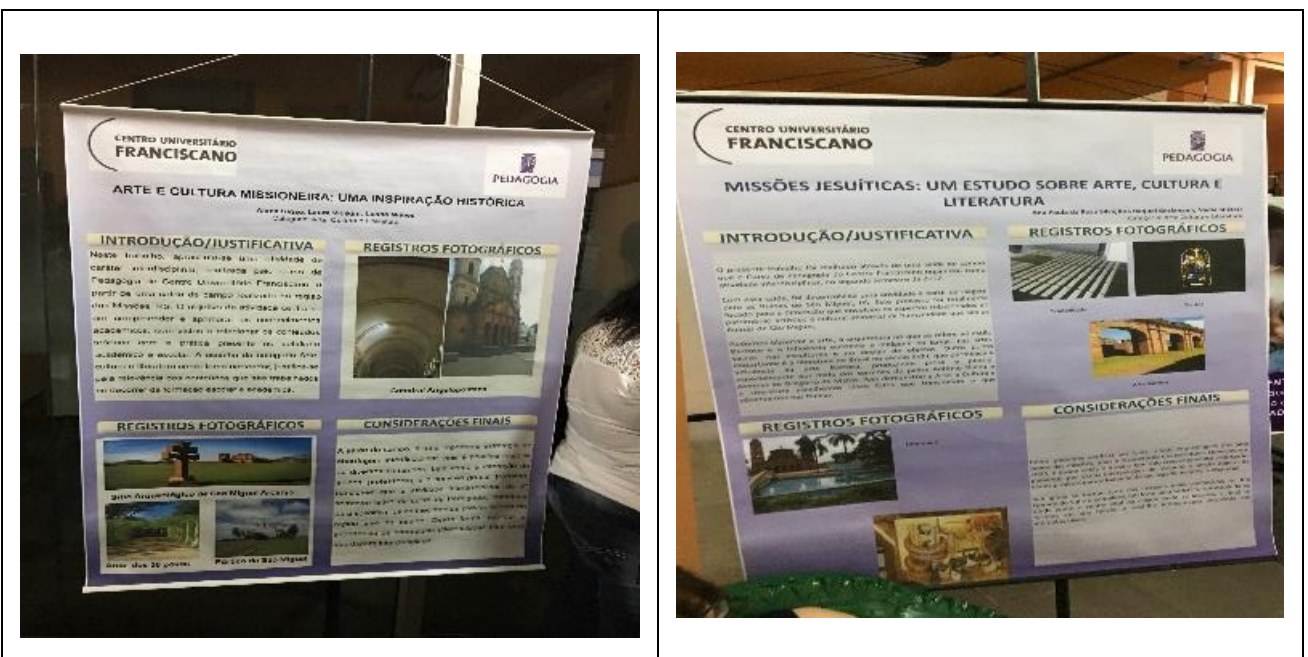

Fonte: As autoras

Os excertos extraídos dos resumos dos grupos de trabalho das estudantes, na sequência deste estudo, destacam a relevância do contexto artístico, histórico e cultural das reduções jesuíticas no estado do RS. Também, foram mencionados aspectos como a arquitetura e arte sacra barroca, as esculturas, a presença remanescente do artesanato dos índios guaranis e o fato de o sítio ter sido declarado patrimônio histórico e cultural pela Organização das Nações Unidas para Educação, Ciência e Cultura (UNESCO), como demonstra nos excertos dos trabalhos das acadêmicas. 


\title{
REVISTA ELETRÔNICA \\ DA GRADUAÇÃO/PÓS-GRADUAÇÃO EM EDUCAÇÃO UFG/REJ
}

"As ruínas compõem um conjunto remanescente da antiga redução jesuítica de São Miguel Arcanjo, integrante dos sete povos das missões. Em 1993, a UNESCO tombou as ruínas como patrimônio Histórico e Cultural da Humanidade” (R. 8).

\begin{abstract}
A história da região é marcada pela colonização da Companhia de Jesus dos padres jesuítas que tiveram importante papel na cultura que na época era de relação da Igreja Católica com índios da região. Alguns pesquisadores denominam este estilo de barroco guarani que congrega a arte produzida pelos índios guaranis missioneiros, durante os 150 anos em que estiveram inseridos dentro da experiência reducional, sob orientação e a serviço dos padres jesuítas (R. 18).
\end{abstract}

O artesanato é confeccionado há séculos pelos povos guaranis. Tradicionalmente, os objetos eram usados no dia a dia em seus rituais e, nos dias de hoje, comercializam o artesanato como fonte de renda e também como forma de manter sua cultura viva. Essa atividade envolve toda a família, que é responsável pela confecção de uma variedade de peças como cestarias, instrumentos musicais, esculturas de madeira e utensílios de caça. O processo de produção do artesanato envolve coleta da matéria-prima na mata sua preparação como corte, secagem e tingimento até a confecção das peças que podem levar dias e semanas (R.16).

A influência de um modelo europeu nas esculturas, bem como a expressão de traços indígenas nas obras observadas, contribuiu para a construção de uma identidade cultural e artística das obras da região e do sítio arqueológico. Importante a contribuição de Cosgrove (2004) ao definir as paisagens culturais subdominantes residuais, como espaços em que se manifestam frágeis testemunhos de uma história local, revelando vestígios de um tempo histórico de outras épocas. O excerto extraído do resumo produzido por duas acadêmicas destaca o legado da herança cultural da região missioneira no território gaúcho: "cabe ainda destacar que até hoje temos influência da cultura guarani em nossos costumes e hábitos: o chimarrão, o charque e na agricultura o cultivo da mandioca e do milho, entre outros" (R.8).

Com relação à literatura presente na região, foram lembrados pelas acadêmicas as lendas e os sermões do Padre Antônio Viera e a poesia de Gregório de Matos, bem como as lendas regionais que fazem referência ao período do barroco na trajetória literária brasileira. A prosa barroca está representada, em primeiro plano, pelo Padre Antônio Vieira, com sua sólida cultura humanística, perícia verbal e militância religiosa 


\section{REVISTA ELETRÔNICA \\ DA GRADUAÇÃO/PÓS-GRADUAÇÃO EM EDUCAÇÃO \\ UFG/REJ}

e o desejo utópico da contrarreforma para uma igreja triunfante nas terras novas da América (BOSI, 2006).

Podemos observar a arte, a arquitetura no que se refere ao estilo barroco e à influência europeia e indígena na igreja, nas artes sacras, nas esculturas e no design de objetos. Outro ponto importante é a literatura no Brasil do século XVIII que permeava a influência da arte barroca, produzindo prosa e poesia especialmente pelos sermões do Padra Antônio Vieira e poemas de Gregório de Matos (R. 17).

Cita-se a lenda M'Boi Guaçu também conhecida como Lenda da Cobra Grande e a lenda Lunar de Sepé. A primeira por apresentar indícios de veracidade, ao nos depararmos com as manchas escuras nas paredes da torre do sino, associado ao surreal de mães desesperadas que entregavam seus filhos à grande cobra. A segunda, por representar a história do grande guerreiro missioneiro, Sepé Tiarajú que havia nascido com um lunar na testa (R. 2).

Ainda se faz possível perceber o intuito de análise da arte por si só, sendo compreendida como viés para a explorar, conhecer, fruir e analisar, criticamente, práticas e produções artísticas e culturais do seu entorno social e de diversas sociedades, em distintos tempos e contextos, para reconhecer e dialogar com as diversidades (BRASIL, 2018, p. 156).

Para as estudantes:

"Com a arte o ser humano é capaz de interpretar o mundo, desenvolve a criatividade tão importante para expressar sentimentos, registrar fatos e solucionar problemas" (R.19).

"Entendemos que a arte e a cultura na educação são transgressoras, possibilitando que cada símbolo daquele momento histórico possa nos envolver, através da sensibilidade, e nos transportar ao mundo imaginário dos fatos históricos da época (R.15).

A Categoria ET ficou mais evidente em seis resumos das acadêmicas, destacando especialmente a localização no território, nacional e do estado do RS, as questões espaço e temporalidade e ocupação humana, a paisagem da região e a saga vivenciadas nas reduções jesuíticas pelos missioneiros e pelos indígenas, as questões sociais e econômicas, as divisas, as guerras e disputas de territórios na demarcação do território sul-brasileiro. Na ideia de Gomes (2007, p. 54):

A relação superior espaço/tempo deve ser vista dialeticamente. Isto significa que a conexão de ambas se manifesta sempre com 


\section{REVISTA ELETRÔNICA \\ DA GRADUAÇÃO/PÓS-GRADUAÇÃO EM EDUCAÇÃO \\ UFG/REJ}

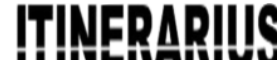 \\ REFLECTONIS}

ISSN. 1807-9342

Volume 14, N. 2, 2018

interdependência e interação. Cada dimensão tem a sua identidade, portanto, sua especificidade, em que não há absorção de uma pela outra, embora ambas estejam simultaneamente ligadas.

A Figura 3 expõe os pôsteres em que as estudantes destacaram os aspectos ET cujas análises serão apresentadas nos excertos dos resumos a seguir.

Figura 3: Pôsteres aspectos Espaço-temporais

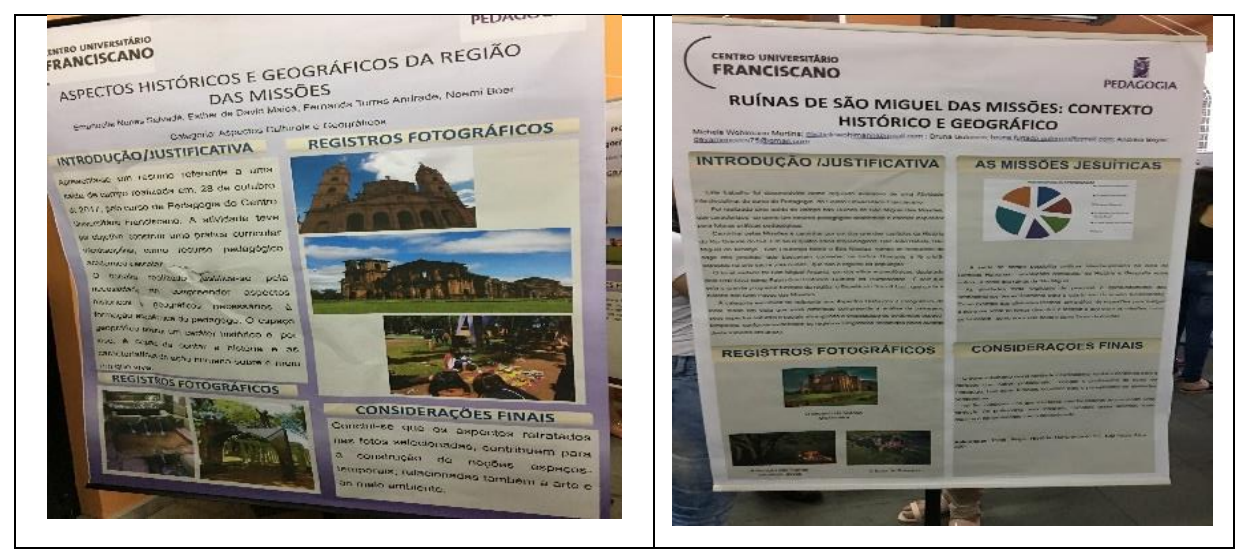

Fonte: As autoras

Nessa direção, as acadêmicas destacam: "São Miguel das Missões é uma cidade gaúcha da região das missões, com pouco menos de dez mil habitantes e fica a $480 \mathrm{~km}$ de Porto Alegre. As ruínas do sítio arqueológico de São Miguel Arcanjo foram construídas pelo Padre Antônio Sepp e tiveram como mão de obra os índios" (R.10).

A partir desse excerto, as estudantes perceberam a relevância de evocar a referência socioespacial, demarcando a cidade de São Miguel das Missões, dentro do estado do Rio Grande do Sul, e a distância da capital, Porto Alegre, incluindo dados acerca da ocupação humana (população) e do espaço (cidade). Essas constatações demarcam que, com a atividade, foi possível estudar a lógica, o sentido e o significado das distribuições espaciais e da organização do espaço e que, nessa lógica, estão inclusas também dimensões culturais (FIZOLA; KOZEL, 2009). Portanto, a alfabetização é relacionada com a vida do aluno e com o espaço que ele constrói, ficando claro que, se o educando não encarar o espaço como algo em que ele está inserido, a natureza que ele próprio ajuda a moldar, a verdade geográfica do indivíduo se perde. Assim, acaba a Geografia, tornando-se alheia a ele. Nas palavras de Castrogiovanni e Costella (2006, p.32): 


\title{
REVISTA ELETRÔNICA \\ DA GRADUAÇÃO/PÓS-GRADUAÇÃO EM EDUCAÇÃO UFG/REJ
}

\begin{abstract}
Alfabetizar cartograficamente não consiste em desmistificar as noções de representação do mundo através de imagens ou mapas, mas, sim construir noções através de propostas concretas oficinas, que permitam uma interpretação espontânea dos sinais gráficos, os quais representam um mapa e a organização dessas representações de maneira coerente, dentro de uma perspectiva do ponto de vista de cada mapeador.
\end{abstract}

O resumo 11 afirma que: "construída a partir de 1687, ali surgiu uma civilização promissora e rica em expressões culturais onde se mesclam elementos europeus e indígenas, sempre com uma forte orientação europeia cristã” (R.11).

Também foi destacada pelas acadêmicas a relevância de conhecer aspectos geográficos e históricos no que diz respeito à ocupação humana, pelos impactos causados na paisagem e na sociedade em geral pela agropecuária. Na região, ocorre em grande extensão territorial a cultura da soja e a criação de gado de corte. Com essa observação, constata-se que as estudantes percebem que o espaço geográfico também foi organizado do ponto de vista econômico, especialmente como área rural e de cultivo de alimentos (FIZOLA; KOZEL, 2009).

A educação geográfica visa a exercitar a capacidade de observação, descrição, interpretação e pensamento crítico diante da realidade, bem como perceber as transformações sofridas pela mesma. Essa realidade envolve sociedade e natureza. Portanto, "Cabe à Geografia levar a compreender o espaço produzido pela sociedade em que vivemos hoje, suas desigualdades e contradições, as relações de produção que nela se desenvolvem e a apropriação que essa sociedade faz da natureza" (OLIVEIRA, 2003, p. 142).

O espaço geográfico possui um caráter histórico e, por isso, é capaz de contar a história e as características da ação humana sobre o meio em que vive. Conclui-se que os aspectos retratados (...) contribuem para a construção de noções de espaço-temporais, relacionados também a arte e ao meio ambiente" (R.11).

Torna-se importante abordar a inserção do ser humano neste processo, tanto em relação à urbanização quanto em relação à agricultura e à industrialização de forma mais específica, trazendo para o ambiente escolar a discussão sobre os rumos que a produção agropecuária e industrial precisa seguir nas próximas décadas (PROENÇA; DALFARRA; OSLAJ, 2017, p. 239).

Com relação à saída de campo, por ser um recurso relevante para o estudo de conteúdos da área das ciências humanas e da natureza, as alunas manifestaram em seus resumos a importância de ter participado de tal experiência. Desse modo, destaca-se no excerto a seguir: 


\section{REVISTA ELETRÔNICA \\ DA GRADUAÇÃO/PÓS-GRADUAÇÃO EM EDUCAÇÃO UFG/REJ}

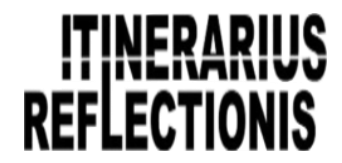

ISSN. 1807-9342

Volume 14, N. 2, 2018

"fazendo a interlocução com a Pedagogia esse tipo de atividade é essencial para o professor trabalhar com projetos nos anos iniciais, desenvolvendo conhecimentos na área da geografia, história, ciências, matemática e arte (R.1).

Assim, a intervenção pedagógica e qualificada do educador dependerá, essencialmente, da qualidade dos processos de formação que percorreu e sobre os quais seja possível construir. O educador constitui-se autor de seu próprio desenvolvimento profissional, à medida que é capaz de incorporar a atitude de reflexão permanente sobre a sua prática educativa, com vistas ao aprimoramento e redimensionamento do traçado pedagógico. Deste modo, percebe-se, no excerto seguinte, tal preocupação: “o trabalho realizado justifica-se pela necessidade de compreender aspectos históricos e geográficos necessários à formação acadêmica de um pedagogo" (R. 11).

Viveiro e Diniz (2009) atestam as reflexões levantadas pelas estudantes, destacando que as atividades de campo se constituem em importantes recursos para explorar uma diversidade de conteúdos. Também, o contato direto com o ambiente motiva os estudantes para a observação, análise, novos questionamentos e, assim, melhorar a compreensão dos fenômenos presenciados.

De acordo com as orientações da BNCC (2018), o Ensino de Geografia pode levar os alunos a compreenderem, de forma mais ampla, a realidade e nela intervir de maneira mais consciente e cidadã. Nesse sentido, o saber geográfico deve possibilitar a reflexão acerca do destino do ambiente humano, bem como dos caminhos alternativos à obtenção de qualidade de vida social. Nesta dimensão, está a possibilidade da construção de uma educação para a sustentabilidade, em que se promova o entendimento de desenvolvimento econômico, sem danificar os recursos do ambiente. Impõe-se ao educador geográfico promover situações de aprendizagem que mobilizem seres humanos em formação a um olhar crítico-reflexivo diante dos recursos do ambiente. A análise da realidade proporciona a construção de um pensamento indagador, questionador, reflexivo. Este pensamento sobre feições reflexiva, imaginativa, instigadora compreende o pensamento científico. Esta reflexão, imaginação, indagação, concebe-se pela percepção humana diante da realidade vivenciada. Essa realidade próxima compreende os espaços locais, constituídos por identidades socioculturais, das quais emerge o sentimento de pertencimento. A mente 


\section{REVISTA ELETRÔNICA \\ DA GRADUAÇÃO/PÓS-GRADUAÇÃO EM EDUCAÇÃO UFG/REJ}

\section{TrWERPRUS REFLECTIONIS}

ISSN. 1807-9342

Volume 14, N. 2, 2018

humana, portanto, passa a se mobilizar para a superação. Neste caminho, então, são agilizadas habilidades, conhecimentos e competências, os quais dão forma ao pensamento científico.

Com relação à categoria $\mathrm{SC}$, mencionada em dois resumos apenas, pode-se perceber que as estudantes, além dos aspectos artísticos, históricos, geográficos e culturais, demarcados pelas outras duas categorias anteriores (artístico-cultural e socioespacial), ainda tiveram um olhar para a dimensão da biodiversidade fauna (presença de diferentes espécies de aves nativas e introduzidas) e flora regional (espécies nativas e introduzidas) presentes, devido aos biomas pampa e mata atlântica, que se manifestam na região.

A Figura 4 expõe os pôsteres em que as estudantes destacaram os aspectos sociocientíficos, cujas análises serão expostas nos excertos dos resumos a seguir.

Figura 4: Pôsteres destacando aspectos sociocientíficos.
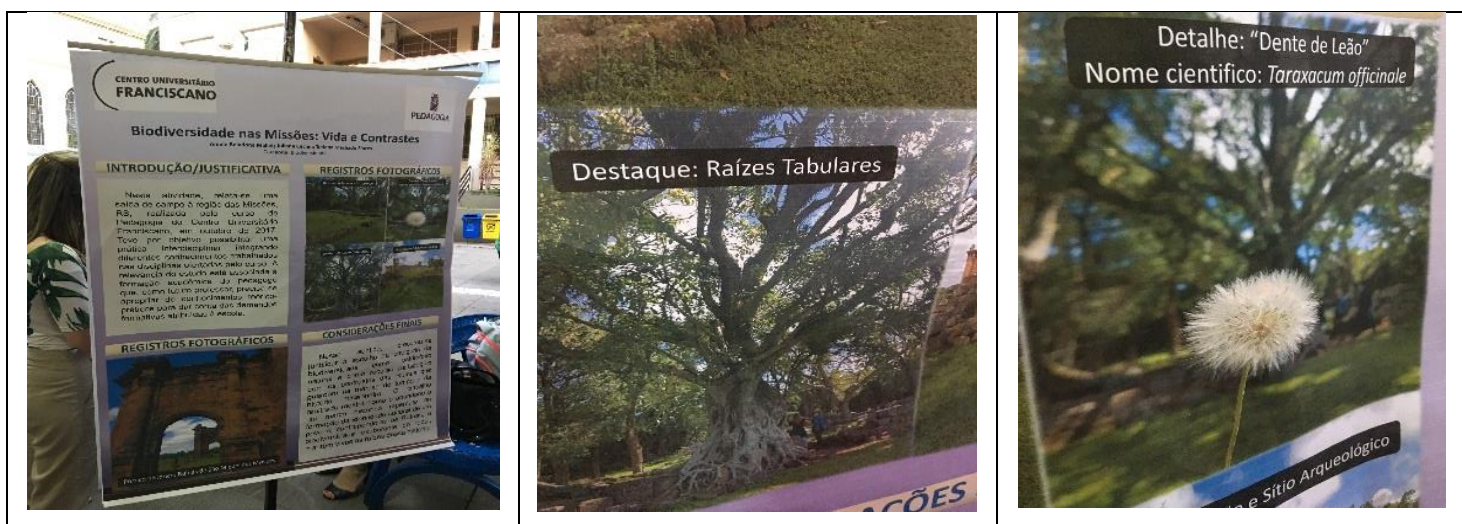

Fonte: As autoras

Assim, as acadêmicas destacam: "A viagem permitiu um olhar à biodiversidade presente no estado do RS, fauna e flora da região missioneira remanescentes dos biomas pampa e mata atlântica" (R.13).

A compreensão das inter-relações entre a fauna e a flora de uma região por parte de estudantes da Educação Básica no ensino de Ciências representa um aspecto fundamental para a Educação Ambiental, especialmente considerando biomas presentes no Rio Grande do Sul, o Pampa e a Mata Atlântica (PROENÇA; DALFARRA; OSLAJ, 2017, p. 219). 


\section{REVISTA ELETRÔNICA \\ DA GRADUAÇÃO/PÓS-GRADUAÇÃO EM EDUCAÇÃO UFG/REJ}

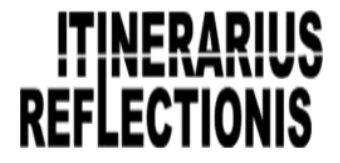

ISSN. 1807-9342

Volume 14, N. 2, 2018

Observamos muitos pássaros como joão-de-barro, bandos de caturritas, rabo de palha, coruja, dentre outros. Uma vegetação rasteira formada por gramíneas e árvores nativas como figueira-do-mato, umbu, pitangueiras e árvores frutíferas que demarcam a presença da espécie humana com o ambiente (R.13).

Como demonstra o excerto anteriormente citado (R13), as estudantes observaram a presença e características morfológicas de plantas herbáceas como o dente-de-leão e árvores nativas como a figueira do mato. Também plantas ornamentais e frutíferas introduzidas pelos moradores da região, bem como os impactos no ambiente da espécie humana, especialmente pelas monoculturas do trigo e da soja na região. "Por ser um conjunto de ecossistemas muito antigos, o Pampa apresenta fauna e flora próprias e grande biodiversidade, com uma vegetação herbácea composta por gramíneas e árvores esparsas" (PROENÇA; DAL-FARRA; OSLAJ, 2017, p.219).

Também as estudantes destacaram o assoreamento dos rios, erosão e pouca biodiversidade. Proença; Dal-Farra e Oslaj (2017) sinalizam que os alunos necessitam conhecer a biodiversidade da fauna e flora especialmente da região onde residem. $\mathrm{O}$ estudo e reconhecimento das espécies nativas e exóticas provocam o respeito, a preservação das mesmas, como também a integração e comprometimento da comunidade com o ambiente e o resgate de aspectos que historicamente o constituíram. Nesse sentido, as estudantes manifestaram: “Também percebemos os impactos causados pela espécie humana na região tanto pelo conflito social ocasionado na época das reduções jesuíticas como atualmente, no entorno das ruínas com ocupação da monocultura da soja e do trigo" (R.13).

As características desse bioma (presença reduzida de árvores frondosas) e pelo relevo dos campos sulinos (compostos praticamente por planícies e colinas) têm possibilitado o manejo dessas paisagens para pecuária pastoril e para a agricultura em larga escala, o que vem impactando significativamente no ambiente. As propícias características ambientais dos ecossistemas do RS permitem a utilização de suas paisagens para diversos fins, principalmente para culturas agrícolas, embora o manejo inadequado, aliado a outros fatores, tenha produzindo significativos impactos ambientais (BRACK, 2007). Nesse sentido, as orientações da Base Nacional Comum Curricular (BNCC) alertam para a necessidade de que sejam incluídos, nos currículos escolares, propostas nas quais 


\section{REVISTA ELETRÔNICA \\ DA GRADUAÇÃO/PÓS-GRADUAÇÃO EM EDUCAÇÃO UFG/REJ}

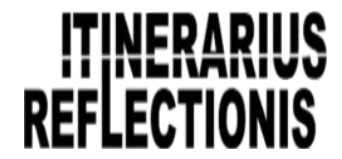

ISSN. 1807-9342

Volume 14, N. 2, 2018

se estudem características dos ecossistemas destacando-se as interações dos seres vivos com outros seres vivos e com os fatores não vivos do ambiente, com destaque para as interações que os seres humanos estabelecem entre si e com os demais seres vivos e elementos não vivos do ambiente. Aborda-se, ainda, a importância da preservação da biodiversidade e como ela se distribui nos principais ecossistemas brasileiros (BRASIL, 2018, p. 278).

A partir da proposta de ensino oportunizada às estudantes do curso de Pedagogia, foi possível perceber que, ao mesmo tempo que refletiram acerca da formação específica com relação às áreas do conhecimento, também conseguiram olhar para a perspectiva de atuarem como professoras ao lembrarem da relevância da atividade voltada ao aprendizado das crianças, como se pode perceber pelas reflexões do excerto abaixo.

Uma saída de campo abre diversas possibilidades para o trabalho pedagógico nos anos iniciais do ensino fundamental. Garante um estudo articulado além de trabalhar com os conhecimentos das ciências sociais, ciências naturais auxiliando no desenvolvimento da reflexão crítica sobre os grupos humanos (...). A experiência concreta de observação detalhada de um ambiente é muito rica para crianças, estabelecendo uma relação de respeito pelas áreas verdes e de apropriação do espaço como um bem coletivo (R. 10).

Afinal, o professor em formação está aprendendo a conciliar os saberes acadêmicos com os saberes e fazeres docentes de modo a promover situações de aprendizagem aos seus alunos, ao passo que está aprendendo também com estas situações propostas, requerendo então criticidade, autonomia e reflexão sobre sua prática para que assim possa emergir uma consciência crítica de seu papel para a Ciência e a Sociedade (SANTOS, et, al. 2017, p.6).

Os excertos das estudantes alinham-se às ideias de Pugliesi et al, (2017) os quais destacam que as atividades de campo são importantes aliadas nos cursos de formação inicial de docentes, atreladas às disciplinas de cunho pedagógico, uma vez que despertam reflexões acerca da profissão, possibilitando assumir uma postura de autonomia e de responsabilidade na implementação de políticas públicas de educação.

\section{CONSIDERAÇÕES FINAIS}

Nesta pesquisa, buscou-se identificar quais os conhecimentos espaço-temporais, sociocientíficos e artístico-culturais são evidenciados pelos estudantes de Pedagogia a partir de uma visita técnica orientada ao sítio histórico das Ruínas de São Miguel das 


\section{REVISTA ELETRÔNICA \\ DA GRADUAÇÃO/PÓS-GRADUAÇÃO EM EDUCAÇÃO UFG/REJ}

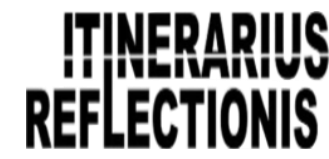

ISSN. 1807-9342

Volume 14, N. 2, 2018

Missões, RS, no segundo semestre de 2017. Constatou-se que as estudantes conseguiram perceber que uma atividade como a saída de campo é capaz de acionar, aprofundar e consolidar conhecimentos de diferentes áreas do saber, bem como viabilizar atitudes e posturas cidadãs e de relacionamento interpessoal. Nesse interim, ao mesmo tempo em que as acadêmicas se percebiam em processo de formação inicial para a docência, também muitas delas conseguiam prospectar os saberes e recursos que estavam aprendendo e vivenciando para outros espaços, como a sala de aula, atuando com crianças.

Defende-se que, na formação inicial para docentes, faz-se necessário abordar metodologias mediadas por diferentes recursos didáticos, a exemplo, da saída de campo, a fim de ofertar experiências didáticas com a finalidade de correlacionar saberes teóricos e práticos, abordados no currículo da formação inicial docente e, desse modo, passíveis de serem transpostos para os espaços escolares da educação básica.

Portanto, a proposta de saída de campo tornou-se um relevante recurso motivador e dinamizador do processo de ensino e aprendizagem das acadêmicas de Pedagogia, visto que, na oportunidade, puderam perceber diferentes contextos e espaços de acesso e aprofundamento dos conhecimentos e, ao mesmo tempo, detectaram os possíveis conteúdos das áreas de conhecimento, como das Ciências da Natureza, Geografia, História e Artes, plausíveis para serem aprendidos tanto nos espaços acadêmicos, bem como ensinados, quando no exercício da docência. Destaca-se, assim, a relevância de ações que privilegiem interlocução entre teoria e prática, fundadas no planejamento didático dos docentes de modo interdisciplinar.

Assim sendo, por meio de recursos didáticos, como a saída de campo orientada, é possível incitar, nos estudantes, a reflexão, a problematização da realidade, a promoção, o aprofundamento e a consolidação de conhecimentos. Também, sem dúvida, acionar novos estudos, posturas e pesquisas voltadas à compreensão do espaço e do fazer pedagógico, de um modo mais criativo e autônomo de se construir como professor.

\section{REFERÊNCIAS}

BARDIN, L. Análise de conteúdo. Lisboa: Edições 70, 2016. 


\section{REVISTA ELETRÔNICA \\ DA GRADUAÇÃO/PÓS-GRADUAÇÃO EM EDUCAÇÃO \\ UFG/REJ}

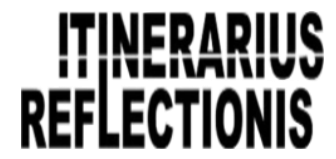

ISSN. 1807-9342

Volume 14, N. 2, 2018

BOSI, A. História concisa da literatura brasileira. São Paulo: Cultriz, 2006.

BOGDAN, R. C.; BIKLEN, S. K. A investigação qualitativa em educação: uma introdução à teoria e aos métodos. Portugal: Porto Editora, 1994.

BRACK, P. As monoculturas arbóreas e a biodiversidade. 2007. Acesso em: jan. 2018. Disponível em: <http://

www.inga.org.br/docs/monoculturas_e_a_biodiversidade.pdf

BRASIL. Ministério de Educação e Cultura. Conselho Nacional de Educação. CNE/CP Resolução $n^{\circ} 1$ de 2006. Diretrizes Curriculares Nacionais do Curso de Pedagogia. Brasília, 2006. Acesso em: 12 set. 2017. Disponível em: http://portal.mec.gov.br/cne/arquivos/pdf/rcp01_06.pdf.

BRASIL. Ministério de Educação e Cultura. Secretaria da Educação Básica. Base Nacional Comum Curricular. Brasília, 2018. Acesso em: 12 jan. 2018. Disponível em: http://basenacionalcomum.mec.gov.br/images/BNCC_20dez_site.pdf.

CAVALCANTI, L. S. Geografia e práticas de ensino. Alternativa: Goiania, 2002.

Geografia, escola e construção de conhecimentos. São Paulo: Papirus, 2003.

CASTROGIOVANNI, A. C; COSTELLA, R. Z. Brincar e cartografar com os diferentes mundos geográficos: a alfabetização espacial. Porto Alegre: EDIPUCRS, 2006.

CHASSOT, Á. Alfabetização científica: questões e desafios para a educação. Ijuí: Editora UNIJUÍ, 2000.

COSGROVE, D. A geografia está em toda parte. In: CORRÊA, R. L.; ROSERDAHL, Z. (Orgs.). Paisagem, tempo e cultura. 2. Ed. Rio de janeiro: EdERJ, 2004.

DELIZOICOV, D.; ANGOTTI, J. A. P.; PERNAMBUCO, M. M. Ensino de ciências: fundamentos e métodos. São Paulo: Cortez. P. 364, 2002.

FIZOLA, R.; KOZEL, S. Teoria e prática do ensino de geografia. São Paulo: FTD, 2009.

GOMES, H. Reflexões sobre a teoria e crítica em geografia. Goiânia: UCG, 2007.

KRASILCHIK, M.; MARANDINO, M. Ensino de ciências e cidadania. São Paulo: Moderna, 2010.

NÓVOA, A. Formação de professores e profissão docente. Lisboa: Dom Quixote, 1992. Acesso em: 16 de jan. 2018. Disponível em: http://repositorio.ul.pt/bitstream/10451/4758/1/FPPD_A_Novoa.pdf. 


\section{REVISTA ELETRÔNICA \\ DA GRADUAÇÃO/PÓS-GRADUAÇÃO EM EDUCAÇÃO UFG/REJ}

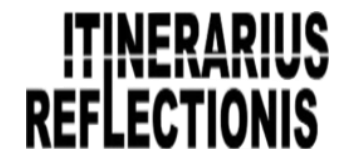

ISSN. 1807-9342

Volume 14, N. 2, 2018

OLIVEIRA, A. U. Educação e ensino de Geografia na realidade brasileira. In:

OLIVEIRA, A. U. et al (Org.). Para onde vai o ensino de Geografia? 8. ed. São Paulo: Contexto, 2003.

PROENÇA, M. S.; DAL-FARRA, R. A., OSLAJ, E. U. Espécies Nativas e Exóticas no Ensino de Ciências: uma Avaliação do Conhecimento dos Estudantes do Ensino Fundamental. Contexto \& Educação. Editora Unijuí. Ano 32 nº 103 Set./Dez. 2017. Acesso em: 12 jan. 2018. Disponível em:

https://www.revistas.unijui.edu.br/index.php/contextoeducacao/article/view/6964/5589.

PUGLIESI, A. et. Al. A atividade de campo como prática reflexiva na formação inicial de professores. Anais. X Encontro Nacional de Pesquisa em Educação em Ciências XI ENPEC. Universidade Federal de Santa Catarina, Florianópolis, SC, 3 a 6 de julho de 2017. Acesso em: jan. 218. Disponível em: http://www.abrapecnet.org.br/enpec/xienpec/anais/resumos/R1775-1.pdf

SCHÄFFER, N. O. Pesquisa em Geografia no Ensino Fundamental in: VERDUM, R. (Org.). Ensino de geografia, planejamento ambiental e gestão territorial. Porto Alegre: Associação de Geógrafos Brasileiros: Porto Alegre, 2001.

SALLES, G. D.; KOVALICZN, R. A. O mundo das Ciências no espaço da sala de aula: o ensino como um processo de aproximação. In: NADAL, B. G. (Org.). Práticas pedagógicas nos anos iniciais: concepção e ação. Ponta Grossa: UEPG, 2007. p. 91-112.

SANTOS, A. F. et al. Ensinar e aprender sobre ciências: reflexões a partir do estágio supervisionado no ensino fundamental. Anais. III Encontro internacional de jovens investigadores (edição Brasil). JOIN Brasil. 12 a 14 de outubro de 2017. Acesso em 21 jan. 2018. Disponível em:www.researchgate.net/profile/Francisco_Santos46/publication/322100533

VIVEIRO, A. A; DINIZ, R. E. da S. Atividades de campo no ensino das ciências e na educação ambiental: refletindo sobre as potencialidades desta estratégia na prática escolar. Ciência em Tela. v. 2, n.1, 2009. Acesso em: jan. de 2018. Disponível em: http://www.cienciaemtela.nutes.ufrj.br/artigos/0109viveiro.pdf 